\title{
RA?EGA
}

O ESPACO GEOGRÁFICO EM ANÁLISE

\section{ANÁLISE MULTICRITERIAL APLICADA A ELABORAÇÃO DE ZONEAMENTO DE UNIDADE DE CONSERVAÇÃO NA ZONA COSTEIRA DA BAHIA, BRASIL}

\section{MULTICRITERIA ANALYSIS APPLIED TO ZONING OF PROTECTED AREAS IN THE COASTAL ZONE OF BAHIA, BRAZIL}

\author{
Elfany Reis do Nascimento Lopes \\ Universidade Estadual Paulista Júlio de Mesquita Filho \\ São Paulo, SP, Brasil \\ e-mail: elfanyl@hotmail.com \\ Roberto Wagner Lourenço \\ Universidade Estadual Paulista Júlio de Mesquita Filho \\ São Paulo, SP, Brasil \\ e-mail: robertow@sorocaba.unesp.br
}

Gil Marcelo Reuss-Strenzel Universidade Estadual de Santa Cruz

Ilhéus, BA, Brasil

e-mail:gmreuss@gmail.com

Recebido em: 04/03/2015

Aceito em: 20/05/2016

\section{Resumo}

Este estudo objetivou demonstrar a aplicação da análise multicriterial (AMC) na elaboração do zoneamento de unidades de conservação situadas na zona costeira do Brasil, utilizando a Área de Proteção Ambiental de Guaibim como exemplo na elaboração de um zoneamento que compatibilizasse conservação dos recursos naturais e desenvolvimento local. A análise multicriterial foi utilizada para adequar a APA à conservação e ao desenvolvimento, através do estabelecimento de critérios advindos do mapa de uso da terra e da ponderação dos pesos de importância pela técnica processo de análise hierárquica e da agregação dos fatores pela técnica da combinação linear ponderada. O mapa de viabilidade à conservação apresentou maiores escores de viabilidade nos extremos territoriais, com áreas de manguezais, brejos (comunidades aluviais), restingas e rios. O mapa de viabilidade ao desenvolvimento sugeriu maiores escores para 0 centro da APA. Posteriormente, os mapas gerados foram integrados através da análise 
multiobjetivo, eliminando os conflitos e acomodando as áreas adequadas a cada objetivo. A Análise multiobjetivo sugeriu cerca de $70 \%$ da área para a conservação e a área de desenvolvimento foi delimitada a 30\% do território, culminando em duas principais zonas de manejo (Zona de Conservação e Zona de Desenvolvimento) e as respectivas subzonas de manejo. A AMC é uma análise indicada na elaboração de zoneamentos de unidades de conservação ou ainda, na atualização destes, capaz de aproximar os resultados obtidos à realidade do território.

Palavras-chave: Tomada de decisão; Sistema de informações geográficas; Zonas de manejo; Análise multiobjetivo.

\begin{abstract}
This study aimed to demonstrate the application of multicriterial analysis (MCA) in the zoning of protected areas located in the coastal zone of Brazil, using the Environmental Protected Area (EPA) of Guaibim (Valença-Bahia), as an example in a zoning that combines conservation of natural resources and local development. The multicriterial analysis was used to fit the EPA to the conservation and development through the establishment of criteria originated of a map of land use and the weighting of importance weights by process of hierarchical analysis technical and aggregation of factors by the linear weighted combination technical. The map of viability for conservation presented higher scores of viability in territorial extremes with mangrove, swamps, sandbanks areas and rivers. The map of viability for development suggested higher scores to the center of the EPA. Later, the generated maps were integrated by the multiple-objective analysis, by eliminating conflicts and accommodating appropriate areas for each objective. The multiple-objective analysis suggested that approximately $70 \%$ of the area for the conservation and development was delimited to $30 \%$ of the territory, culminating in two main areas of management (Conservation Area and Area of Development) and management subareas. The AMC is an analysis indicated the preparation of zoning of protected areas or, in its update, with ample capacity to reflect the reality of the territory and assist in conflict resolution during the decision process.
\end{abstract}

Keywords: Decision-making; Geographic information system;Management zones; Multiple-objective analysis

\title{
1. INTRODUÇÃO
}

No ano 2000, o Brasil estabeleceu o Sistema Nacional de Unidades de Conservação da Natureza - SNUC (BRASIL, 2000) como estratégia de conservação dos recursos naturais do seu território. Esse sistema prevê a definição de áreas de grande biodiversidade como unidades de conservação 
(UCs), que podem ser distinguidas entre unidades de proteção integral ou de uso sustentável (LOPES, 2013).

Para gerir essas unidades, é preciso aliar-se a instrumentos e ferramentas metodológicas que integrem diferentes informações, subsidiando o ordenamento e fomentando a conservação destas áreas. Um segundo fator na gestão das áreas protegidas, dá-se na compatibilização de objetivos conflitantes, que em geral, estão entre a necessidade de conservar os recursos naturais e o desenvolvimento local. Em UCs de uso sustentável, essa relação é constante, considerando a possibilidade de exploração indireta dos recursos (LOPES; REUSS-STRENZEL, 2015).

Quando as UCs encontram-se situadas ao longo da zona costeira brasileira, os problemas na gestão são ainda mais enfáticos, já que, estas áreas apresentam beleza cênica de grande valor e faixas de praias que conferem ao longo do tempo, diferentes intervenções, dentre elas, a ocupação desordenada.

Para ordenar o território das áreas protegidas brasileiras, o SNUC estabeleceu além do plano de manejo, o zoneamento como instrumentos de elaboração e instituição obrigatórios (BRASIL, 2000). E para ordenar o território da zona costeira brasileira o Plano Nacional de Gerenciamento Costeiro do Brasil (PNGC) criado em 1988, também instituiu o zoneamento como instrumento necessário à legalização das atividades (BRASIL, 1988), devendo assim, se complementarem na gestão da UCs e do território costeiro.

O zoneamento é definido como o instrumento que investiga as relações entre os aspectos ecológicos e econômicos do território e a negociação das atividades na UC, servindo para a adoção de políticas públicas de desenvolvimento e de conservação dos recursos naturais (VEIGA, 2001; BRASIL, 2002; 2011; REMPEL et al., 2012; SILVA et al., 2012; VASCONCELOS et al., 2013).

O zoneamento deve ser também, o resultado de um processo políticoadministrativo, em que os conhecimentos técnicos e científicos são imprescindíveis para a adequação à realidade ambiental e socioeconômica da área zoneada, tornando-se uma tarefa complexa de tomada de decisão sobre 
os vários atributos da terra para minimizar o efeito do impacto na ocupação (GENELETTI; DUREN, 2008; LOPES et al., 2012; THOMAS, 2012).

$\mathrm{Na}$ elaboração de propostas de zoneamentos, o uso inovador da tecnologia torna-se fundamental, reforçando a importância do Sistema de Informações Geográficas (SIG) como ferramenta para a gestão dos recursos naturais. A análise multicriterial (AMC) quando ambientada em SIG é uma ferramenta de auxílio ao zoneamento, melhorando a definição das zonas de manejo e a espacialização dos atributos da terra (NAUGTHON, 2007; CHANG et al., 2008; THOMAS, 2012; OHADI et al., 2013; HABTEMARIAM; FANG, 2016).

A AMC é considerada um auxílio para a análise ambiental na perspectiva do sistema aberto e dinâmico, permitindo uma maior conexão com a realidade quando se considera a relação ponderada entre as variáveis analisadas dentro das peculiaridades de cada território. A análise sintetiza os dados complexos e multidimensionais, em que, o decisor procura ordenar elementos de um conjunto de alternativas do melhor ao pior. (MIARA; OKAFIORI, 2007; PONPERMAYER, 2007; FRANCISCO et al., 2008; EASTMAN, 2012a).

O objetivo da AMC é ajudar o gestor a analisar dados complexos, buscando a melhor estratégia de gestão do meio ambiente, considerando diversas alternativas que se resumem em: uma decisão a ser tomada; os eventos desconhecidos que podem afetar os resultados; os possíveis cursos de ação e os próprios resultados (VILAS BOAS, 2005; PONPERMAYER, 2007; EASTMAN, 2012a; OLIVEIRA et al., 2014).

O uso da análise mostrou-se eficiente na elaboração de diferentes zoneamentos em áreas protegidas terrestres e marinhas em todo o mundo, tendo o seu uso, justificado pela possibilidade de ponderar diversas variáveis, culminando em resultados abrangentes a nível espacial (JOERIN et al., 2001; VILLA et al., 2002; CHANG et al., 2008; GENELETTI; DUREN, 2008; MOEINADDINI et al., 2010; PENG et al., 2012; ZHANG et al., 2013; HABTEMARIAM; FANG, 2016). 
No Brasil, a AMC aliada ao SIG ainda é pouco difundida em estudos ambientais, especialmente para ordenar e conservar áreas situadas ao longo da zona costeira. Trabalhos realizados no Brasil são pontuais, registrando pesquisas no planejamento de recursos hídricos, do solo e no zoneamento (ZUFFO et al., 2002; PINESE JÚNIOR; RODRIGUES, 2012; LOBO, 2009; ROSOT et al., 2007; FRANCISCO et al., 2008; VALE et al., 2008; TAVANTI et al., 2009), confirmando a necessidade de difusão dessas ferramentas, que apresentam alto potencial na otimização do processo decisório.

Considerando o exposto, este artigo objetivou demonstrar a aplicação da análise multicriterial na elaboração do zoneamento de unidade de conservação situada na zona costeira do Brasil, utilizando a Área de Proteção Ambiental (APA) de Guaibim (Valença, Bahia, Brasil) como um exemplo de UC para a produção de um zoneamento que compatibilizasse a conservação dos recursos naturais e o desenvolvimento local.

Visando atingir ao objetivo da produção do zoneamento, foram estabelecidos como objetivos específicos para este estudo: aplicar a AMC através do processo de análise hierárquica e da combinação linear ponderada para mapear áreas da APA de Guaibim viáveis à conservação e ao desenvolvimento; aplicar a AMC através da análise multiobjetivo para combinar os mapas de viabilidade à conservação e ao desenvolvimento, visando eliminar os conflitos existentes e acomodar as respectivas áreas sobre o território da APA de Guaibim; e propor zonas e subzonas de manejo, situando as suas características e objetivos.

\section{MATERIAIS E MÉTODOS}

\subsection{Descrição da área de estudo}

A APA de Guaibim, categorizada como uma unidade de conservação de uso sustentável encontra-se situada no município de Valença no estado da Bahia, delimitando-se a oeste pela rodovia estadual BA 001, a nordeste pelo Rio Jequiriçá, a sudeste pelo Rio dos Reis, ao sul pelo Canal de Taperoá e foz do Rio Una e a Leste pelo Oceano Atlântico (Figura 1). 
Criada pela Lei Estadual 1.164/1992 com uma área territorial de 2.000ha (BAHIA, 1992), teve em 2002, através do poder municipal, uma sobreposição territorial para a criação da Área de Proteção Ambiental da Planície Costeira do Guaibim, com extensão de aproximadamente 13.000ha pelo decreto municipal 424/2007 (VALENÇA, 2007). A ampliação da unidade de conservação teve como fundamento a alta exploração da área com o turismo costeiro e a ocupação urbana em seu interior.

Na APA, o levantamento do uso da terra realizado por Lopes e ReussStrenzell (2015) revelou uma área urbana associada a uma malha viária consolidada, além de áreas agrícolas com cultivos de espécies distintas, pastagens e criação de gado. As formações vegetais encontradas na APA são denominadas por restingas, manguezais, brejos (comunidades aluviais), remanescentes de floresta ombrófila densa e rios.

A economia do distrito de Guaibim baseia-se na pesca artesanal, no turismo, orla marítima com barracas de praias e uma rede hoteleira diversificada, que recebem turistas durante todo o ano. A empresa de carcinicultura Valença da Bahia Maricultura S/A com uma área de cultivo e beneficiamento de camarão, além do Aeroporto de Valença e o Terminal Atracadouro do Bom Jardim também compõem a economia do distrito e respondem pela geração de emprego e renda para a população. 

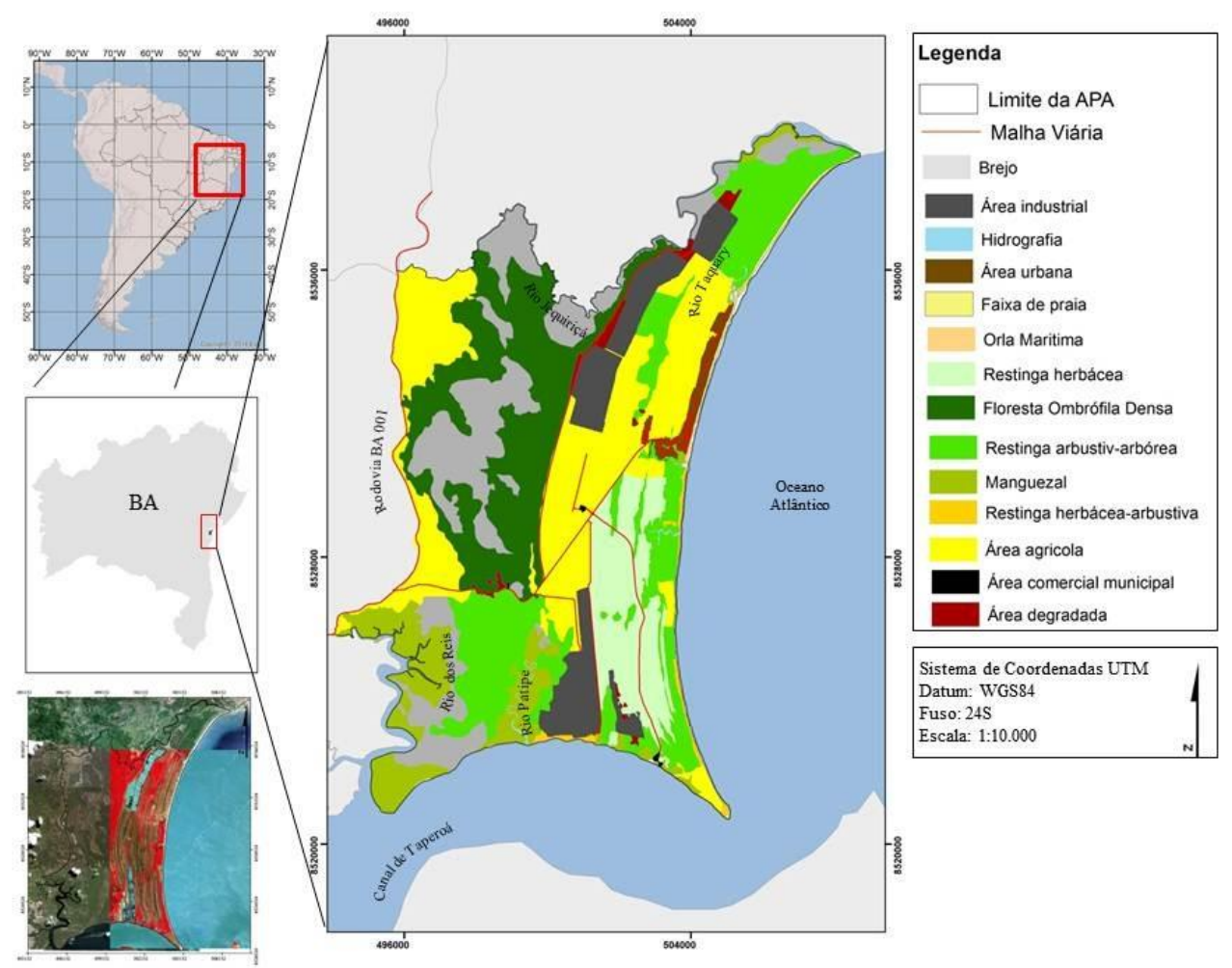

Figura 1: Localização e levantamento do uso da terra e cobertura vegetal da Área de Proteção Ambiental de Guaibim, Valença, Bahia.

Fonte: Adaptado de Lopes e Reuss-Strenzel (2015).

\subsection{Análise Multicriterial}

Para a aplicação da AMC, foram determinados dois cenários de análise e proposta uma metodologia composta de três etapas, descritas abaixo:

\section{Cenários da análise}

Cenário de conservação: a vertente biofísica, com seus atributos físicos e bióticos, foi a base para a tomada de decisão, buscando atender o objetivo de conservar os recursos naturais.

Cenário de desenvolvimento: a vertente socioeconômica foi a base para a tomada de decisão, buscando atender ao objetivo de garantir o fomento socioeconômico e cultural do distrito de Guaibim e do município de Valença.

\section{Etapa I - Delimitação dos critérios e ponderação dos pesos}

Os critérios foram selecionados com base em um mapa digital em escala 1:10.000 do uso da terra e cobertura vegetal, elaborado a partir da interpretação visual de imagens satélites do satélite RapidEye, obtidas em 
2009, que pode ser observado com maior detalhe em Lopes e Reuss-Strenzel (2015). Além disso, confeccionou-se um mapa de Área de Preservação Permanente (APPs) e um mapa de unidades geológicas, compondo dessa forma os critérios de análise (Quadro 1).

O mapa de APPs foi confeccionado a partir da ferramenta buffer no software ArcGis (ESRI, 2013), segundo o preconizado pelo código florestal brasileiro (BRASIL, 2012). As APPs foram geradas a partir dos vetores da rede hidrográfica e das fisionomias vegetais de brejos, restingas e manguezais oriundos do mapa de uso da terra e cobertura vegetal. Como a APA se concentra em área plana, com ausência de declividade que se enquadre em área de APPs, tal característica não foi considerada para o respectivo mapa.

A confecção do mapa de unidades geológicas foi realizada a partir da delimitação das unidades através da edição manual de vetores, dentro do território da APA de Guaibim, segundo o mapa do quaternário costeiro da Bahia (MARTIN et al., 1980).

Quadro 1: Critérios utilizados para a aplicação da análise multicriterial com o objetivo de mapear áreas viáveis à conservação e ao desenvolvimento da APA de Guaibim, Valença, Bahia

\begin{tabular}{|c|c|}
\hline Objetivo & Critérios \\
\hline 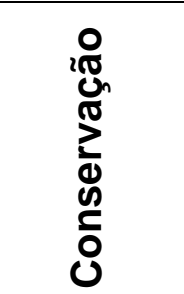 & $\begin{array}{l}\text { 1. Proximidade com as APPs (Quanto menor a distância, melhor). } \\
\text { 2. Vegetação (Quanto mais frágil a vegetação, maior importância) } \\
\text { 3. Unidades geológicas (Quanto mais frágil a estrutura, maior } \\
\text { importância). } \\
\text { 4. Distância da malha viária (Quanto maior a distância, melhor). } \\
\text { 5. Distância da área urbana (Quanto maior a distância, melhor). }\end{array}$ \\
\hline 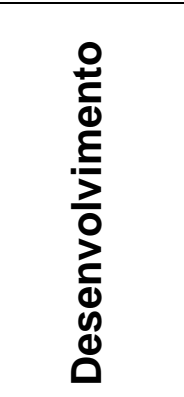 & $\begin{array}{l}\text { 1. Distância das APPs (Quanto maior a distância, melhor). } \\
\text { 2. Proximidade da área turística (Quanto mais próxima, melhor) } \\
\text { 3. Proximidade da área urbana (Quanto mais próxima, melhor). } \\
\text { 4. Proximidade de áreas comerciais, agrícolas e industriais (Quanto } \\
\text { mais próxima, melhor). } \\
\text { 5. Proximidade da Malha Viária (Quanto menor a distância, melhor). }\end{array}$ \\
\hline
\end{tabular}

Os vetores representando cada critério foram convertidos para o formato raster no software Idrisi Selva (EASTMAN, 2012b). Em seguida, por meio da 
função stretch, todos os critérios foram convertidos em fatores padronizados numa escala variando entre 0 e 255 escores.

Por meio do módulo Decision wizard, aplicou-se o Processo de Análise Hierárquica $(\mathrm{PAH})$, estabelecendo pesos de importância para cada fator através de uma matriz de comparação pareada, seguindo o preconizado por Saaty (1977).

\section{Etapa II - Agregação dos fatores}

A etapa consistiu na aplicação da técnica Combinação Linear Ponderada (CLP) para agregar os fatores e obter os mapas de viabilidade para cada cenário (EASTMAN, 2012a). Nesta técnica, os fatores são combinados multiplicando cada célula ou pixel, de cada mapa pelo seu peso e, então, soma-se os resultados (SARTORI; ZIMBACK, 2012).

Os mapas finais são apresentados numa escala padronizada entre 0 a 255 escores, em que 0 corresponde às áreas menos favoráveis e 255 às áreas mais favoráveis para atendimento do objetivo determinado.

\section{Etapa III - Análise multiobjetivo (AMO)}

Nesta última etapa da $\mathrm{AMC}$, os mapas de adequação foram combinados, buscando eliminar os conflitos e acomodar as áreas mais viáveis a cada objetivo dentro de um mesmo território. Na Análise Multiobjetivo (AMO), os objetivos foram considerados como conflitantes, já que o desenvolvimento instituído requer a exploração dos recursos naturais, que em contrapartida, devem ser conservados, especialmente porque na APA de Guaibim, grande parte dos recursos são considerados APPs.

Inicialmente, ambos os mapas foram ranqueados e suas áreas reclassificadas foram integradas para obtenção de um mapa de conflito, a partir do módulo Crosstab no Idrisi Selva. O propósito dessa etapa é conhecer as áreas passíveis de atender ambos os objetivos, as quais serão consideradas na resolução de impasses durante a AMO. 
A análise foi efetuada através do módulo Mola, e estabelecidos os pesos de 0,7 para o objetivo de conservação e de 0,3 para o objetivo de desenvolvimento. Os pesos são empregados para resolver conflitos entre os objetivos em cada pixel (EASTMAN, 2012a).

\section{Viabilidade do uso da terra e cobertura vegetal}

O mapa de uso da terra e cobertura vegetal foi convertido em raster no Idrisi Selva e utilizado no módulo Extract do Idrisi Selva, para se obter as médias e o desvio padrão de cada atividade em relação à sua viabilidade para os objetivos de conservação e de desenvolvimento.

\subsection{Zoneamento}

O Zoneamento foi obtido após a execução das etapas anteriores (Figura 2), sendo a delimitação das zonas realizada através do resultado da AMO e das subzonas de manejo pela reclassificação das atividades dentro de cada zona.

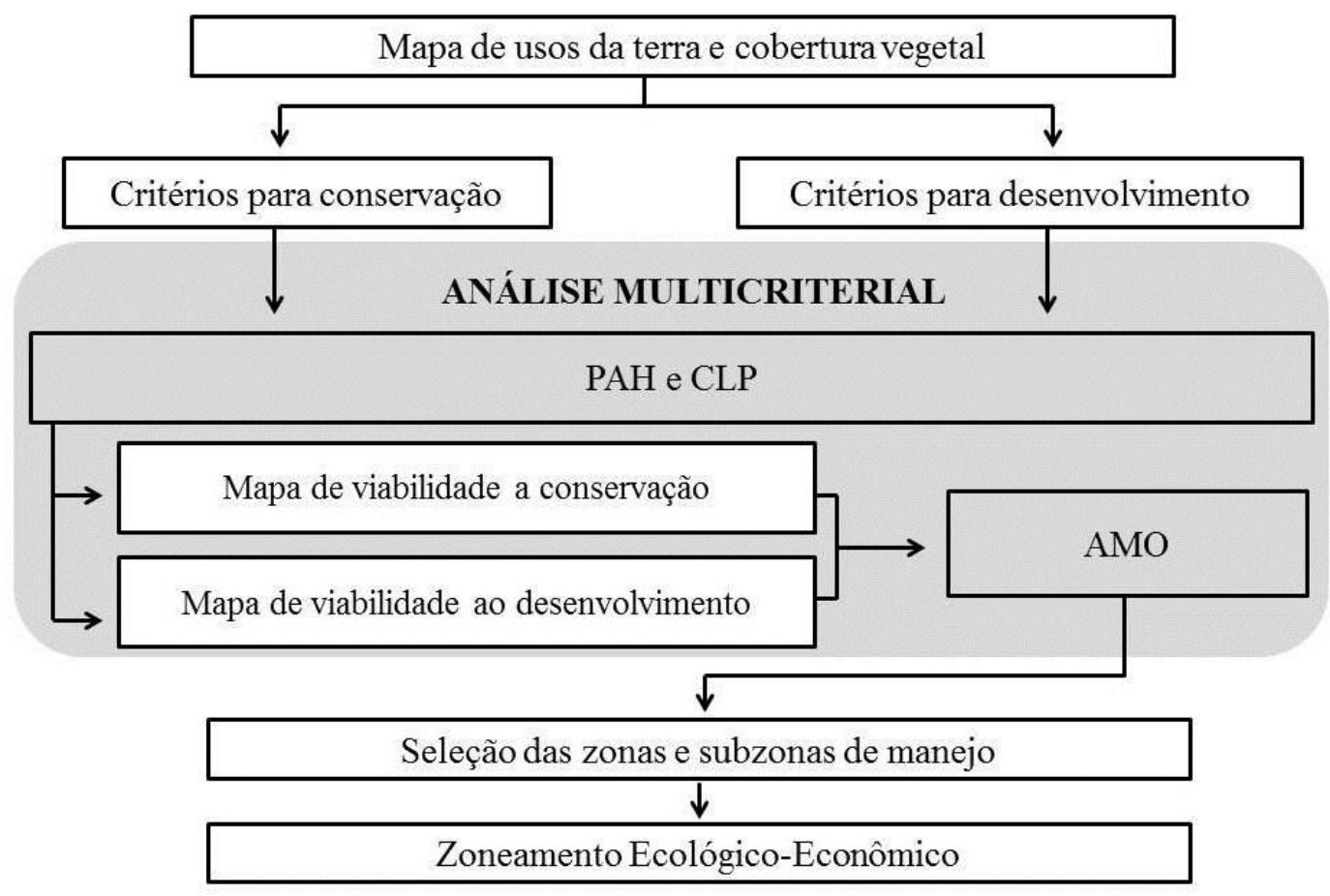

Figura 2: Etapas executadas para determinação do Zoneamento da APA de Guaibim, Valença, Bahia. 
ANÁLISE MULTICRITERIAL APLICADA A ELABORAÇÃO DE ZONEAMENTO DE UNIDADE DE CONSERVAÇÃO NA ZONA COSTEIRA DA BAHIA, BRASIL

\section{RESULTADOS E DISCUSSÃO}

Os critérios escolhidos para a AMC apresentaram ampla cobertura territorial da APA de Guaibim e concordância com a escala de prioridade relacionada aos objetivos propostos, podendo ser considerados coesos e pertinentes para o estudo. Após o cálculo dos pesos, o Grau de Consistência (GC) foi realizado para atestar a coerência com que os pesos foram atribuídos na matriz de comparação de cada análise (Tabelas 2 e 3) (SAATY, 1977).

Neste estudo, o grau de consistência obtido foi de 0,08 e 0,03 entre os fatores de conservação e desenvolvimento, respectivamente. Estes valores encontram-se dentro do valor máximo permitido de 0,10 e, aproximam-se também, do grau de consistência obtido por Peng et al. (2012) que variou entre 0,01 e 0,10 nas diferentes comparações realizadas no estudo e por Zhang et al. (2013) que obtiveram 0,08 na consistência dos pesos para uma proposta de zoneamento na China.

Tabela 1: Matriz de comparação com os pesos atribuídos aos fatores para atingir o objetivo de conservação da APA de Guaibim, seus respectivos pesos finais e grau de consistência. Legenda: PAPP - Proximidade com as Áreas de Preservação Permanente. VEG - Vegetação. UG - Unidades Geológicas. DAU - Distância da Área Urbana. DMV - Distância da Malha Viária. GC - Grau de Consistência.

\begin{tabular}{l|cccccc}
\hline \multicolumn{1}{c}{ Fatores } & PAPP & VEG & UG & DAU & DMV & Peso Final \\
\hline PAPP & 1 & & & & & 0.06 \\
VEG & 1 & 1 & & & & 0.06 \\
UG & 1 & 1 & 1 & & & 0.06 \\
DAU & 5 & 5 & 5 & 1 & & 0.26 \\
DMV & 5 & 5 & 5 & 5 & 1 & 0.53 \\
\hline
\end{tabular}

Tabela 2: Matriz de comparação com os pesos atribuídos aos fatores para atingir o objetivo de desenvolvimento da APA de Guaibim, seus respectivos pesos finais e grau de consistência. Legenda: DAPP - Distância das Áreas de Preservação Permanente. PAT - Proximidade da Área Turística. PMV - Proximidade da Malha Viária. PCCA Proximidade da Área Comercial, de Carcinicultura e Agrícola. PAUR - Proximidade da Área Urbana. GC - Grau de Consistência

\begin{tabular}{l|cccccc}
\hline \multicolumn{1}{c}{ Fatores } & DAPP & PAT & PMV & PCCA & PAUR & Peso Final \\
\hline DAPP & 1 & & & & & 0.54 \\
PAT & $1 / 5$ & 1 & & & & 0.14 \\
PMV & $1 / 5$ & 1 & 1 & & & 0.10 \\
PCCA & $1 / 5$ & $1 / 3$ & 1 & 1 & & 0.09 \\
PAUR & $1 / 5$ & 1 & $1 / 3$ & 1 & 1 & 0.10 \\
\hline & & & & & & GC $=0.03$ \\
\hline
\end{tabular}


O mapa de viabilidade à conservação refletiu o peso dados aos fatores, estabelecendo maior importância para a distância da malha viária $(0,53)$, seguida da área urbana $(0,26)$, a proximidade das áreas de APPs $(0,06)$, da vegetação $(0,06)$ e das características geológicas $(0,06)$. O mapa pode ser observado na Figura 3[A], no qual as áreas mais viáveis à conservação estão localizadas nos extremos territoriais da APA.

Essa configuração privilegiou que as áreas estivessem distantes da malha viária e, consequentemente, da área urbana. Como estes fatores encontram-se amplamente desenvolvidos no centro da APA, justifica-se a indicação das áreas extremas para serem conservadas. Os maiores escores de viabilidade estão representados ao norte por manguezais, restinga e brejos (comunidades aluviais) e ao sul por manguezais, brejos e rios.

Estes locais compõem de fato, áreas com maior grau de conservação, já que são as mais distantes do centro da UC e possuem acesso dificultado, sendo, além de áreas primitivas e com ausência de ocupação, uma importante área úmida e estuarina de preservação permanente da APA de Guaibim, com destaque para a conservação da biodiversidade costeira.

As áreas com baixos escores de conservação são caracterizadas por áreas com cultivos agrícolas, cultivo e beneficiamento de camarão, área urbana consolidada com malha viária desenvolvida e ampla utilização para o turismo.

O mapa de viabilidade ao desenvolvimento observado na Figura 3[B] apresentou os maiores escores de viabilidade no centro da APA. Os pesos refletiram maior importância para a distância das APPs $(0,54)$, seguidos da proximidade com a área turística $(0,14)$, da proximidade da malha viária $(0,11)$, da proximidade com a área urbana $(0,11)$, e por último, a proximidade com a área comercial, de carcinicultura e agrícola $(0,09)$.

Áreas situadas ao noroeste e ao sul, representadas por cultivos agrícolas, pastagens e carcinicultura, também foram sugeridas ao desenvolvimento. Os altos escores de viabilidade apresentam-se fortemente associadas à influência humana, principalmente pelo desenvolvimento do turismo em períodos de alta temporada com serviços de restaurantes, orla marítima e ocupação hoteleira de aproximadamente 95\%. 
A maior importância dada à área turística pode ser reflexo da atual ênfase na economia local e municipal, da qual o município mantém a geração de emprego e renda e o distrito de Guaibim apresenta maior visibilidade no cenário turístico nacional. Os maiores escores concentraram-se em faixas distantes das APPs, que do ponto de vista legal, seus usos devem ser restringidos ou minimizados visando o baixo impacto ambiental em ecossistemas terrestres e aquáticos (BRASIL, 2000; 2012).
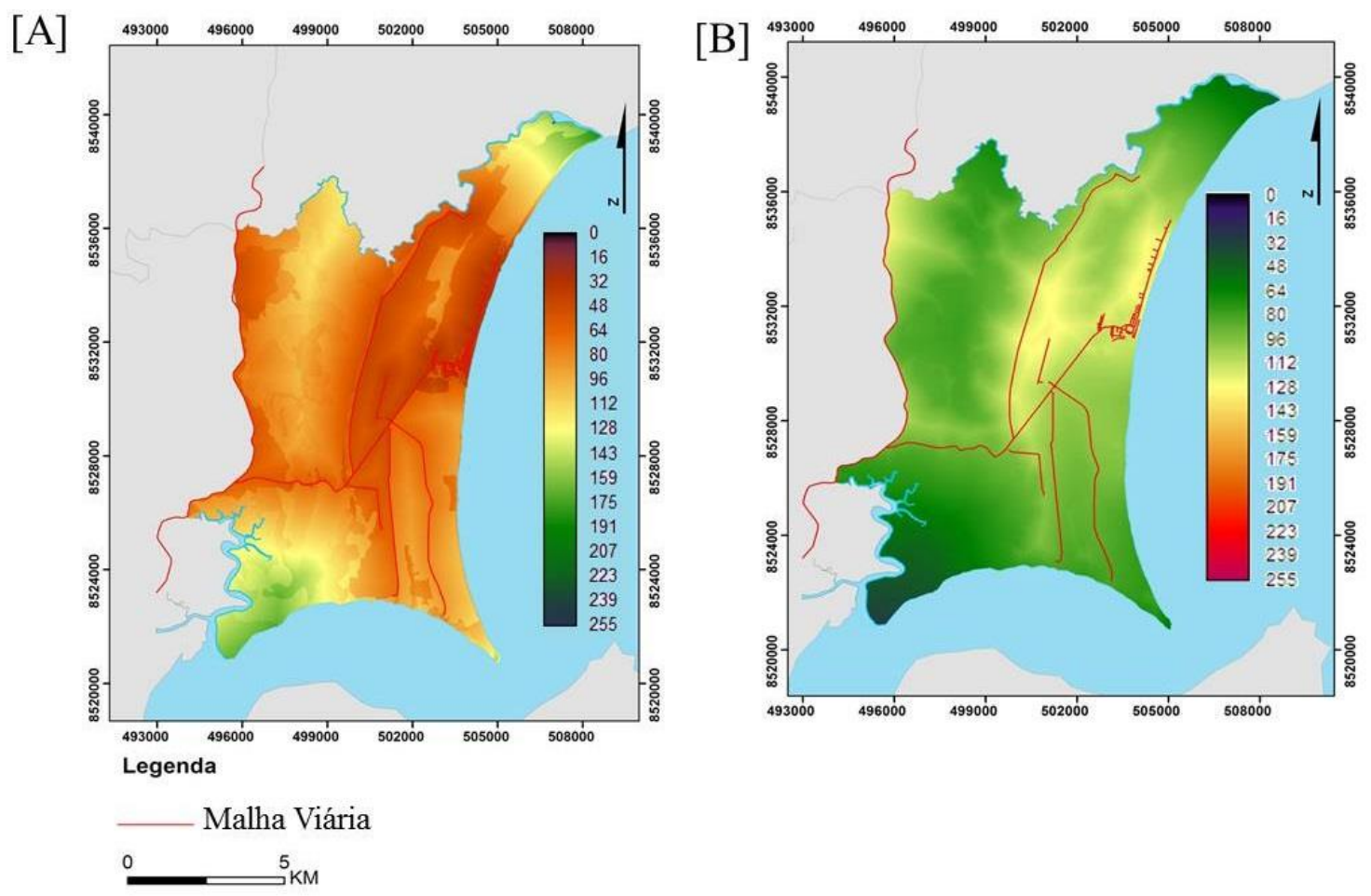

Figura 3:[A] Mapa de viabilidade de conservação para APA de Guaibim, Valença, Bahia. [B] Mapa de viabilidade de desenvolvimento para APA de Guaibim, Valença, Bahia.

A escolha dos fatores para atingir diferentes objetivos durante a aplicação da AMC foi uma importante etapa da análise. Para o zoneamento da APA de Guaibim, os fatores de proximidade com as APPs, distância da malha viária e da área urbana foram definidos para o objetivo de conservação, enquanto o oposto foi determinado para o desenvolvimento, através dos fatores distância das APPs, a proximidade com a malha viária e com a área urbana, podendo assim, esperar-se que a maior parte das áreas viáveis ao objetivo de 
conservar sejam as menos viáveis do objetivo de desenvolvimento, fato observado neste estudo.

Os escores médios obtidos para os objetivos de conservação e desenvolvimento foram avaliados para cada uso atual observado na APA (Figura 4). As áreas úmidas, representadas pelos manguezais, brejos (comunidades aluviais) e as áreas cobertas por restingas herbácea-arbustiva e arbustiva-arbórea, apresentaram maiores escores médios de conservação.

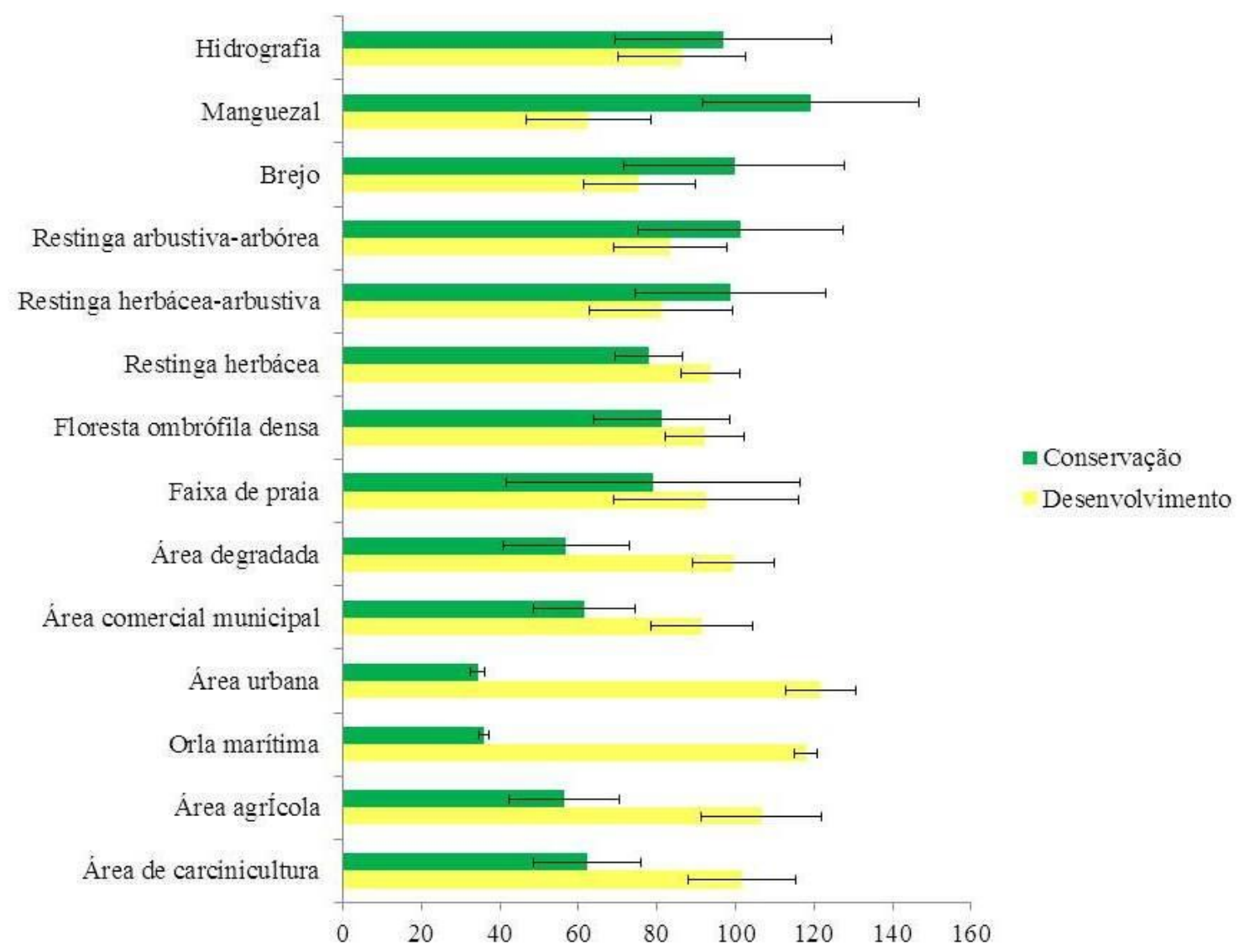

Figura 4: Escores de viabilidade das classes atuais de uso da terra e cobertura vegetal para atender aos objetivos de conservação e desenvolvimento na APA de Guaibim.

A restinga herbácea, floresta ombrófila densa e a faixa de praia, por outro lado, apresentaram escores médios ligeiramente superiores para desenvolvimento. Esse fato pode ser justificado pela proximidade destas áreas com os fatores utilizados na análise de viabilidade ao desenvolvimento, logo embora, estas áreas não devam assumir necessariamente tal objetivo, considerando a necessidade de proteção da biodiversidade nestes locais. 
As áreas com aptidão tipicamente socioeconômica designadas pela área urbana, a orla marítima, a área agrícola e de carcinicultura tiveram escores médios mais elevados para o objetivo de desenvolvimento, confirmando-as como atividades viáveis ao desenvolvimento.

Os resultados revelam que a AMC auxilia análise territorial e pode ser utilizada para a elaboração de propostas de zoneamento com base nos critérios utilizados neste estudo, ou ainda, na inclusão de outros. Essa vantagem coloca a AMC como uma ferramenta potencial na tomada de decisão ambiental, delineando a possibilidade de inclusão de novas características e a reavaliação dos resultados obtidos em tempo real.

No que concerne ao PAH e CLP como técnicas da AMC em estudos de zoneamentos, Anh et al. (2014) indicaram a PAH como eficiente na quantificação do desenvolvimento socioeconômico no meio ambiente e Zahirianet et al. (2012) enfatizaram a importância da CLP para determinar a conservação dos recursos naturais.

Diversos estudos também empregaram a técnica PAH na determinação dos pesos e a CLP para a agregação dos fatores em propostas de zoneamentos e adequação de usos da terra, com resultados semelhantes aos encontrados nessa pesquisa (JOERIN et al., 2001; VILLA et al., 2002; GENELETTI; DUREN, 2008; MOEINADDINI et al., 2010; PENG et al., 2012; ZHANG et al., 2013). Com auxilio das técnicas, os estudos delimitaram diferentes planos de zoneamentos, correspondendo e adequando-se a realidade de seus territórios, e, sobretudo, auxiliaram os gestores durante o processo de tomada de decisão de onde restringir ou permitir as atividades.

Para Sartori e Zimback (2012) as informações ambientais geradas a partir do uso da CLP apresentam alto potencial para apoiar o planejamento racional do uso dos recursos naturais, da ocupação territorial e auxílio no desenvolvimento de políticas públicas e processos de tomada de decisão. Tal afirmação é corroborada pelos resultados obtidos neste estudo, já que a agregação dos fatores possibilitou a indicação de áreas capazes de atender objetivos específicos e facilitará a tomada de decisão relacionada com as restrições de atividades no zoneamento produzido. 


\section{ANÁLISE MULTICRITERIAL APLICADA A ELABORAÇÃO DE ZONEAMENTO DE UNIDADE DE CONSERVAÇÃO NA ZONA COSTEIRA DA BAHIA, BRASIL}

Contudo, ressalta-se que não existe um método específico para ser utilizado no delineamento do zoneamento, já que há uma necessidade de adequar-se às características da área, às questões políticas e administrativas, ao objetivo e tamanho da UC, além da disponibilidade da base de dados e de recursos financeiros (HABTEMARIAM; FANG, 2016).

Com o cruzamento dos mapas de viabilidade a conservação e ao desenvolvimento, a Figura 5[A] demonstra a área em conflito, ou seja, a área capaz de atender a ambos os objetivos dentro da APA de Guaibim, o que também é reflexo da alta dispersão em torno da média apresentado por algumas classes de usos da terra.

Essa área conflituosa encontra-se localizada no centro da APA e próxima ao limite com a rodovia BA 001, ocupadas por áreas comerciais, agrícolas, de carcinicultura, urbana, turística, áreas de vegetação de restinga, brejos (comunidades aluviais), manguezais, floresta ombrófila densa e rios, que juntas somam 610 hectares.
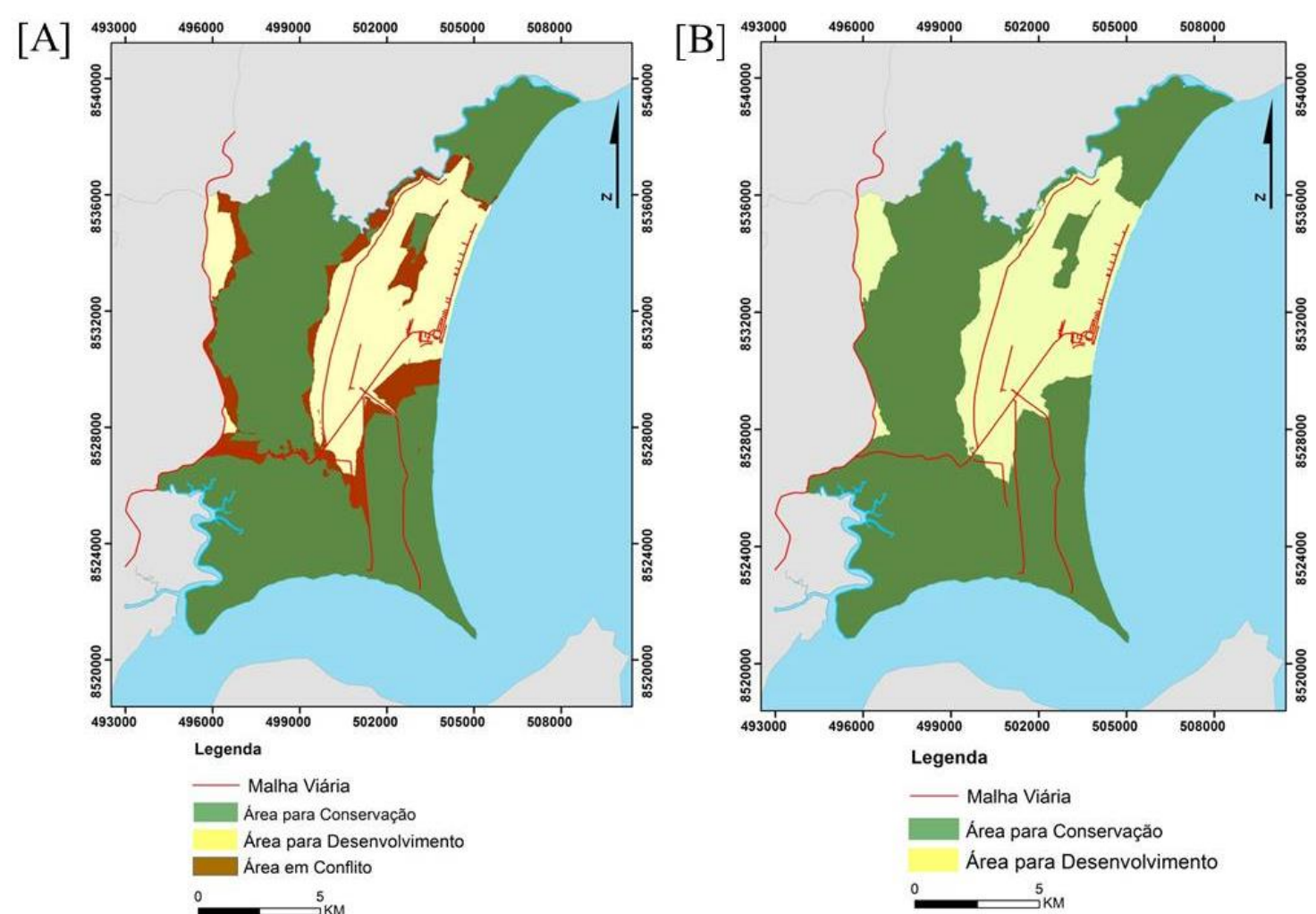

Figura 5:[A] Mapa de conflito entre os objetivos de conservação e desenvolvimento na APA de Guaibim. [B] Mapa resultante da análise multiobjetivo (AMO), indicando as áreas viáveis à conservação e ao desenvolvimento na APA de Guaibim, Valença, Bahia. 
$\mathrm{Na} \mathrm{AMO}$, a melhor combinação de pesos para acomodar as zonas a serem ocupadas por cada objetivo, foi 0,7 para conservação e 0,3 para desenvolvimento, utilizados para resolver os impasses da área de conflito identificada. Esse processo possibilitou a delimitação no Zoneamento das duas principais zonas de manejo: Zona de Conservação, que inclui $70 \%$ do território da APA e a Zona de desenvolvimento, que inclui os $30 \%$ restantes (Figura $5[\mathrm{~B}])$.

O uso da AMC multiobjetivo foi de grande utilidade para segregação de áreas quando se deseja atender objetivos distintos em um único território. Assim como no zoneamento produzido por Zhang et al.(2013), foi possível comprovar a capacidade da AMC em segregar os altos valores de aptidão para os fins de conservação, das áreas adequadas ao desenvolvimento. Já no estudo de Habtemariam e Fang (2016) a ausência de técnica similar forçou os autores a adequar individualmente as áreas que atendiam aos diferentes objetivos propostos.

A identificação das atividades no interior de cada zona possibilitou a sua reclassificação em subzonas de manejo, que priorizou a continuidade dos usos consolidados da APA, de modo a favorecer o seu desenvolvimento e a conservação local. Foram definidas as seguintes subzonas: Zona de Conservação (subzona de preservação permanente, subzona de uso controlado, subzona de recuperação ambiental) e Zona de Desenvolvimento (subzona de agroindustrial, subzona de uso especial e subzona urbanaturística).

A Tabela 4 apresenta a extensão territorial das subzonas de manejo propostas para a APA de Guaibim. A zona de conservação foi subdividida em três subzonas, das quais a de preservação permanente obteve maior extensão territorial, alcançando $59,2 \%$ desta zona. A Zona de desenvolvimento teve a subzona agroindustrial ocupando a maior parte de seu território $(20,7 \%)$. 


\section{ANÁLISE MULTICRITERIAL APLICADA A ELABORAÇÃO DE ZONEAMENTO DE UNIDADE DE CONSERVAÇÃO NA ZONA COSTEIRA DA BAHIA, BRASIL}

Tabela 3: Extensão territorial das subzonas de manejo do zoneamento da APA de Guaibim

Classe

\section{Zona de Conservação}

Subzona de Preservação Permanente Área (ha) Área (\%)

Subzona de Uso Controlado

Subzona de Recuperação Ambiental

$1,2 \quad 9,7$

\section{Zona de Desenvolvimento}

Subzona Agroindustrial

0,1

0,4

Subzona de Uso Especial

Subzona Urbana-turística

A Figura 6 apresenta a espacialização da proposta de Zoneamento para a APA de Guaibim, com suas respectivas Zonas e subzonas de manejo. Ressalta-se a necessidade de um ajuste dos limites das subzonas dentro da proposta de zoneamento, para que as mesmas tornem-se aplicáveis, adequando-se aos limites das classes atuais de usos da terra. O Quadro 2 apresenta a descrição de cada zona e subzonas com suas características e objetivos.

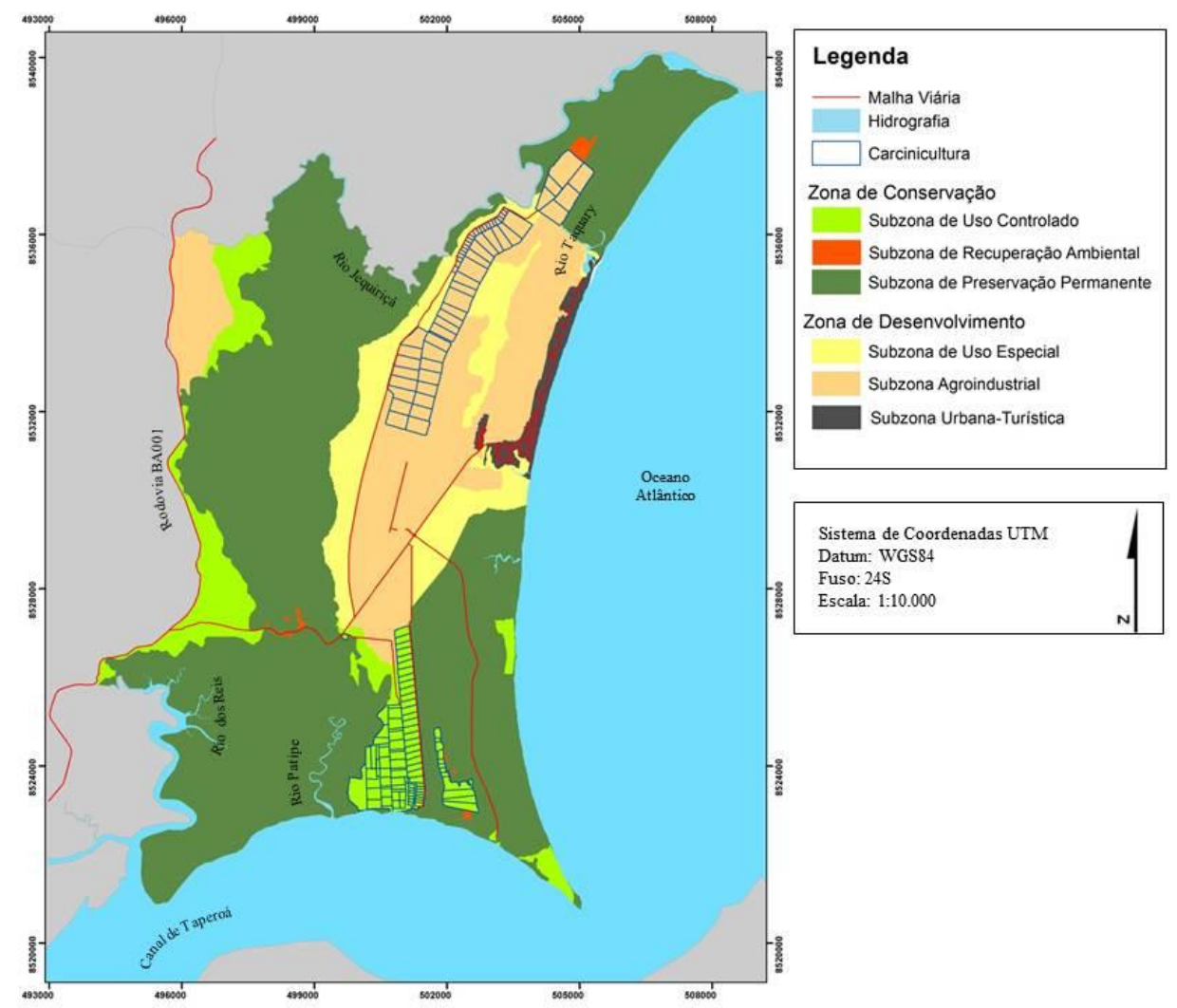

Figura 6: Proposta de Zoneamento para a APA de Guaibim, Valença, Bahia. 
LOPES, E. R. N.; LOURENÇO, R. W.; REUSS-STRENZEL, G. M.

\section{ANÁLISE MULTICRITERIAL APLICADA A ELABORAÇÃO DE ZONEAMENTO DE UNIDADE DE CONSERVAÇÃO NA ZONA COSTEIRA DA BAHIA, BRASIL}

Quadro 2: Descrição das zonas e subzonas da proposta de zoneamento da APA de Guaibim, Valença, Bahia.

\begin{tabular}{|c|c|c|c|}
\hline Zona & \multicolumn{2}{|l|}{ Características } & Objetivo \\
\hline Conservação & \multicolumn{2}{|c|}{$\begin{array}{l}\text { Zona com rica composição vegetacional, } \\
\text { com presença de áreas de restinga, brejos } \\
\text { (comunidades aluviais), manguezais e } \\
\text { floresta ombrófila densa de terras baixas, } \\
\text { delimitadas como áreas de preservação } \\
\text { permanente. A zona caracteriza-se também } \\
\text { por áreas de cultivos agrícolas, } \\
\text { carcinicultura e urbana, que ressaltam a } \\
\text { necessidade de monitoramento ambiental. }\end{array}$} & $\begin{array}{l}\text { Conservar } \\
\text { recursos naturais, } \\
\text { assegurando a } \\
\text { existência da } \\
\text { biodiversidade local, } \\
\text { conciliando-os com } \\
0 \text { desenvolvimento } \\
\text { da APA, com vista } \\
\text { ao uso sustentável. }\end{array}$ \\
\hline Subzona & \multicolumn{3}{|c|}{ Objetivos } \\
\hline $\begin{array}{l}\text { Preservação } \\
\text { Permanente }\end{array}$ & \multicolumn{3}{|c|}{$\begin{array}{l}\text { Preservação das áreas úmidas e da biodiversidade marinha nas } \\
\text { áreas estuarinas; } \\
\text { Preservação das áreas brejosas e das restingas no âmbito da flora } \\
\text { e fauna; } \\
\text { Preservação da Floresta Ombrófila Densa e das espécies que nela } \\
\text { residem; } \\
\text { Conservação da hidrografia local. } \\
\text { Desenvolvimento de pesquisas científicas e educacão ambiental. }\end{array}$} \\
\hline Uso Controlado & \multicolumn{3}{|c|}{$\begin{array}{l}\text { Controlar as atividades socioeconômicas ocorrentes no entorno das } \\
\text { degradação sobre os recursos da APA de Guaibim. }\end{array}$} \\
\hline $\begin{array}{c}\text { Recuperação } \\
\text { Ambiental }\end{array}$ & \multicolumn{3}{|c|}{$\begin{array}{l}\text { Recuperar as áreas degradadas com o reflorestamento de } \\
\text { espécies nativas, em áreas florestais; } \\
\text { Readequação do uso da terra exposta, com o indicativo de } \\
\text { correção de atividades potencialmente degradadoras; } \\
\text { Manter cobertura vegetal em áreas com solo exposto, evitando a } \\
\text { erosão e lixiviação do solo. } \\
\text { Desenvolvimento de pesquisas científicas na área de recuperação } \\
\text { de áreas degradadas. }\end{array}$} \\
\hline Zona & Características & \multicolumn{2}{|c|}{ Objetivos } \\
\hline Desenvolvimento & $\begin{array}{l}\text { Zona com atividades socioeconômicas } \\
\text { consolidadas ou em potencial } \\
\text { crescimento, servindo à economia local } \\
\text { e municipal, com geração de emprego e } \\
\text { renda para a população, em especial } \\
\text { pela área turística da APA, que } \\
\text { apresenta grande importância para o } \\
\text { seu desenvolvimento. A zona apresenta } \\
\text { ainda, uma área composta por recursos } \\
\text { naturais compreendidos por rios, } \\
\text { restingas, manguezais, brejos e floresta } \\
\text { ombrófila densa de terras baixas. }\end{array}$ & & $\begin{array}{l}\text { Isolidar, manter e } \\
\text { r as atividades } \\
\text { ioeconômicas da } \\
\text { A de Guaibim, com } \\
\text { as a assegurar a } \\
\text { lidade urbana, } \\
\text { stica e comercial, } \\
\text { ciliando as atividades } \\
\text { entes a esta zona, } \\
\text { los recursos naturais } \\
\text { diante o uso } \\
\text { tentável. }\end{array}$ \\
\hline Subzona & \multicolumn{3}{|l|}{ Objetivos } \\
\hline Uso Especial & \multicolumn{3}{|c|}{$\begin{array}{l}\text { Utilização sustentável da área, com vistas a conservação dos } \\
\text { recursos naturais, desenvolvimento de pesquisas cientificas e } \\
\text { atividades de educação ambiental, de acordo com os objetivos da } \\
\text { APA de Guaibim, a fim de garantir o seu caráter de unidade de } \\
\text { conservação de uso sustentável. }\end{array}$} \\
\hline
\end{tabular}




\begin{tabular}{|c|l|}
\hline Agroindustrial & $\begin{array}{l}\text { Desenvolver e consolidar os cultivos e fazendas agrícolas e a } \\
\text { atividade de carcinicultura existente, fomentando a economia local } \\
\text { e municipal de forma sustentável. }\end{array}$ \\
\hline Urbana-Turística & $\begin{array}{l}\text { Utilização sustentável da área, visando à consolidação das áreas } \\
\text { urbana e turística, além da preservação cultural da população. }\end{array}$ \\
\hline
\end{tabular}

$\mathrm{Na}$ zona de conservação, a área definida como subzona de uso controlado, incluiu áreas com cultivos agrícolas, carcinicultura e a área de transporte marítimo. Como estas áreas apresentam potencial de degradação ambiental e foram incluídas em área de conservação, faz-se necessário estabelecer medidas compensatórias para o impacto ambiental causado, mediadas por Termos de Ajustamento de Conduta (TAC), especificamente em seu encerramento.

No caso das áreas cultivadas torna-se necessário o controle das espécies produzidas, do uso de agrotóxico e da contaminação dos recursos hídricos. Para as áreas de carcinicultura é fundamental reavaliar e ajustar o cultivo de camarão, com as medidas estabelecidas nas condicionantes do processo de licenciamento ambiental da atividade.

Nas imediações do transporte marítimo, é importante traçar medidas de controle para o acesso a esta via, considerando que a malha viária principal é amplamente desenvolvida nas proximidades de APPs. Além disso, é importante delimitar e regulamentar as áreas de estacionamento que têm levado ao soterramento de restingas e manguezais no Atracadouro de Guaibim.

Na zona de desenvolvimento, a área delimitada para a subzona de uso especial, abriga áreas de restingas, brejos, manguezais e de fragmentos de floresta ombrófila densa da mata atlântica, além de áreas degradadas e rios. Nestas imediações o uso dos recursos deve ser realizado de forma sustentável, as áreas de manguezais podem ser utilizadas para a pesca de espécies de bivalves e crustáceos, uma vez que a categoria APA definida pelo SNUC permite o uso indireto dos recursos naturais de forma sustentável (BRASIL, 2000).

As áreas degradadas podem ser utilizadas como zonas de recuperação para a aplicação de medidas compensatórias mencionadas anteriormente, ou 
ainda na criação de sedes, centro de visitação e pontos de apoio para a prática de turismo ecológico.

Os resultados revelam que o processo de organização dos dados até a tomada de decisão é determinante para alcançar o objetivo final: o zoneamento proposto. Nesse caso, a escolha dos critérios e o grau de importância devem ser visualizados como etapas cruciais durante a aplicação da AMC, levando-se em consideração que o conhecimento da área é um aspecto importante para chegar às decisões.

Esses resultados foram alcançados junto ao potencial da AMC, que embora pareça complexa, auxilia processos de tomada de decisão no âmbito da gestão e planejamento ambiental de UCs. Com base na escolha dos critérios pelos tomadores de decisão é possível chegar em diferentes concepções e reavaliações no momento de definir os diversos níveis de usos, assim como foi demonstrado neste estudo (GENELETTI; DUREN, 2008; HABTEMARIAM; FANG, 2014).

É preciso salientar, que o zoneamento se constitui por um instrumento associado ao plano de manejo das UCs, e no caso daquelas situadas na zona costeira brasileira, deve ser alinhado também com o plano de gerenciamento costeiro. Neste sentido, a associação de ambos os instrumentos, confere maior eficiência no ordenamento territorial e na conservação dos recursos naturais.

No caso do zoneamento da APA de Guaibim, a proposta elaborada com a utilização da AMC foi projetada segundo os objetivos de criação da APA, e delimitou a partir de cada zona de manejo, ações que variam desde um elevado nível de proteção dos ecossistemas, usos razoáveis de extrativismo, educação, pesquisas científicas e turismo, valorizando dessa forma, a conciliação entre o conservar e o desenvolver (DAY, 2002; LU; SHEN; CHIAU, 2014).

A proposta incluiu ainda, os preceitos de conservação e proteção dos recursos naturais, renováveis e não renováveis, dos sistemas fluviais, estuarinos, restingas, florestas litorâneas e manguezais inclusive aquelas incluídas em áreas de preservação permanente estabelecidos tanto no Plano 
Nacional e Estadual de Gerenciamento Costeiro, quanto no plano de manejo da APA (BRASIL, 1988).

\section{CONCLUSÃO}

Na APA de Guaibim, os caminhos delineados pela AMC permitiram alcançar um zoneamento exeqüível ao nível da realidade da APA. A zona de conservação englobou cerca de $70 \%$ do seu território, sendo que as áreas mais viáveis estão em seus extremos, que abrigam manguezais, restingas, brejos (comunidades aluviais) e rios. Uma área de uso controlado foi proposta a fim de garantir a conservação dos recursos naturais.

As áreas viáveis ao desenvolvimento concentraram-se no centro da APA, com áreas consolidadas de turismo, agricultura e carcinicultura. Uma área de uso especial, que favorece o caráter sustentável da APA, foi proposta para possibilitar a realização de atividades de uso indireto. Tais áreas encontram-se próximas à malha viária, confirmando um desenvolvimento direcionado para a área central.

$\mathrm{Na}$ utilização da análise multicriterial, os critérios de distância e proximidade dos atributos ambientais e o grau de importância determinado para atingir os objetivos de conservação e desenvolvimento mostraram-se eficientes na condução da tomada de decisão sobre os locais onde permitir atividades socioeconômicas e ambientais sobre uma UC de uso sustentável.

Recomenda-se que o conhecimento sobre o território analisado seja a peça chave para a utilização da $A M C$, e, portanto, os critérios devem ser estabelecidos de acordo com as características do território e com os seus objetivos finais, podendo ser os mesmos deste estudo, ou ainda, características peculiares a cada área avaliada.

Igualmente, a eliminação de conflitos entre os objetivos por meio da AMC multiobjetivo leva o tomador de decisão a buscar caminhos para solucionar impasses para a gestão do território e, permite, com base nos resultados encontrados, alcançar os objetivos finais da análise.

Assim, a AMC é uma ferramenta de auxilio ao gestor ambiental e pode ser adotada em estudos de planos de zoneamentos ou atividades similares no 
país, uma vez que, os resultados obtidos na elaboração do zoneamento da APA de Guaibim foram satisfatórios e adequados à realidade do território de UCs com múltiplos usos e conflitos diários.

\section{REFERÊNCIAS}

ANH, K.; PHONEKEO, V.; MY, V. C.; DUONG, N. D.; DAT, P.T. Environmental hazard mapping using GIS and AHP - A case study of Dong Trieudistrict in Quang Ninh Province, Vietnam. Earth and Environmental Science, Canadá, v. 18, p. 01-06, 2014.

BAHIA. Decreto no 1.164, de 11 de maio de 1992. Dispõe sobre a criação da Área de Proteção Ambiental de Guaibim, no Município de Valença e dá outras providências. Bahia, 1992.

BRASIL. Lei 7.661 de 16 de maio de 1988. Institui o Plano Nacional de Gerenciamento Costeiro e dá outras providências. Brasília, 1988.

BRASIL. Lei no 9.985, de 18 de Julho de 2000. Regulamenta o artigo 225, § $1^{\circ}$, incisos I, II, III e VII da Constituição Federal, institui o Sistema Nacional de Unidades de Conservação da Natureza e dá outras providências. Brasília, 2000.

BRASIL. Decreto 4.297 de 10 de Julho de 2002. Regulamenta o art. 9ํ, inciso II, da Lei no 6.938, de 31 de agosto de 1981, estabelecendo critérios para o Zoneamento Ecológico- Econômico do Brasil - ZEE, e dá outras providências. Brasília, 2002.

BRASIL. Ministério do Meio Ambiente. Programa de Zoneamento Ecológico Econômico. Brasília: Ministério do Meio Ambiente, 2011. Disponível em: http://www.mma.gov.br. Acesso em: 19 de janeiro de 2015.

BRASIL. Lei no 12.651, de 25 de Maio de 2012. Dispõe sobre a proteção da vegetação nativa; altera as Leis nos 6.938, de 31 de agosto de 1981, 9.393, de 19 de dezembro de 1996, e 11.428, de 22 de dezembro de 2006; revoga as Leis nos 4.771, de 15 de setembro de 1965, e 7.754, de 14 de abril de 1989, e a Medida Provisória no 2.166-67, de 24 de agosto de 2001; e dá outras providências. Brasília, 2012.

CHANG, N.B.; PARVATHINATHAN, G.; BREEDEN, J.B. Combining GIS with fuzzy multi-criteria decision-making for landfill sitting in a fast- growing urban region. Journal of Environmental Management, Filadélfia, v. 87, p. 139-153, 2008. 
DAY, J. Zoning-lessons from the Great Barrier Reef marine park Ocean. Coastal Management, Abingdon, v. 45, p. 139-156, 2002.

EASTMAN, J.R. IDRISI Selva: guide to GIS and image processing. Worcester: Clark Labs, Clark University. 2012a.

EASTMAN, J.R. IDRISI Selva - GIS and Image Processing Software - version 17.0. Worcester-MA/USA: Clark Labs, 2012b.

ECONOMIC AND SOCIAL RESEARCH INSTITUTE (ESRI). ArcGIS. 2013.

FRANCISCO, C. E. S.; COELHO, R. M.; TORRES, R. B.; ADAMI, S. F. Análise multicriterial na seleção de bacia hidrográfica para recuperação ambiental. Ciência Florestal, Santa Maria, v. 18, n. 1, p. 1-13, 2008.

GENELETTI, D.; DUREN, I. V. Protected area zoning for conservation and use: a combination of spatial multicriteria and multiobjective evaluation. Landscape and Urban Planning, China, v. 85, p.97-110, 2008.

HABTEMARIAM, B. T.; FANG, Q. Zoning for a multiple-use marine protected area using spatial multi-criteria analysis: The case of the Sheik Seid Marine National Park in Eritrea. Marine Policy, Pensilvânia, v. 63, p. 135-143, 2016.

JOERIN, F.; THÉRIAULT, M.; MUSY, A. Using GIS and outranking multicriteria analysis for land-use suitability assessment. International Journal of Geographical Information Science,Londres, v. 15, n. 2, p. 153-174, 2001.

LOBO, H. A. S. Zoneamento ambiental espeleológico (ZAE): aproximação teórica e delimitação metodológica. Pesquisas em Turismo e Paisagens Cársticas, Curitiba, v. 2, n. 2, p.113-129. Disponível em: http://www.sbe.com.br/ptpc/ptpc v2 n2 113-129.pdf. Acesso em: 20 de janeiro de 2015.

LOPES, J. L. S.; CESTARO, L. A.; KELTING, F. M. S. Zoneamento ambiental como instrumento de uso da terra do município de Aquiraz-CE. Boletim Goiano de Geografia, Goiânia, v. 32, n.1, p. 93-104, 2012.Disponível em http://dialnet.unirioja.es/descarga/articulo/4785481.pdf. Acesso em 15 de janeiro de 2015.

LOPES, E. R. N. Aspectos ambientais e históricos do sistema ncional de unidades de conservação: 12 anos de implantação. Nature and Conservation, Aquidabã, v. 6, n. 2, p. 6-17, 2013.

LOPES, E. R. N.; REUSS-STRENZELL, G. M. Geoprocessamento aplicado ao monitoramento da ocupação de unidades de conservação - um olhar sobre a Área de Proteção Ambiental de Guaibim. Revista de Geografia da UFPE, Recife, v. 32, n. 3, p. 43-59, 2015. 
LU, S.; SHEN, C.; CHIAU, W. Zoning strategies for marine protected areas in Taiwan: case study of Gueishan Island in Yilan County, Taiwan. Marine Policy, Pensilvânia, v. 48, p. 21-29, 2014.

MARTIN, L.; BITTENCOURT, A.C.S.P.; VILAS BOAS, G.S.; FLEXOR, J.M. Mapa Geológico do Quaternário Costeiro do Estado da Bahia - 1:250.000 - Texto Explicativo. Salvador: Secretaria de Minas e Energia. 1980.

MIARA, M. A.; OKA-FIORI, C. Análise por múltiplos critérios para a definição de níveis de fragilidade ambiental - um estudo de caso: bacia hidrográfica do rio Cará-Cará, Ponta Grossa/PR. Revista RA'E GA, Curitiba, n. 13, p. 85-98, 2007.

MOEINADDINI, M.; NEMATOLLAH, K.; AFSHIN, D.; ALI, A. D.; MEHDI, Z. Y. Siting MSW landfill using weighted linear combination and analytical hierarchy process (AHP) methodology in GIS environment (case study: Karaj). Waste Management, Estados Unidos, v. 30, p. 912-920, 2010.

NAUGHTON, L. Collaborative land use planning: zoning for conservation and development in protected áreas. Tenure Brief, Estados Unidos, n. 4, p. 1-16, 2007.

OHADI, S.; DORBEIKI, M.; BAHMANPOUR, H. Ecotourism Zoning In Protected Areas Using GIS. Advances in Environmental Biology, Ammam, v. 7, n. 4, p. 677-683, 2013.

OLIVEIRA, F.; OLIVEIRA, C. H. R.; LIMA, J. S. S.; MIRANDA, M, R.; RIBEIRO FILHO, R. B.; TURBAY, E. R. M. G.; FERRAZ, F.. Definição de áreas prioritárias ao uso público no parque estadual da Cachoeira da Fumaça - ES, utilizando geoprocessamento. Revista Árvore, Viçosa, v. 38, n. 6, p.10271036, 2014. Disponivel em: http://dx.doi.org/10.1590/S010067622014000600007. Acesso em 21 de abril de 2016. ISSN 0100-6762.

PENG, S.; SHIED, M.; FAN, S. Potential Hazard Map for Disaster Prevention Using GIS-Based Linear Combination Approach and Analytic Hierarchy Method. InternationalJournal of Geographicallnformation Systems,Londres, v. 4, p 403-411, 2010.

PINESE JÚNIOR, J. F.; RODRIGUES, S. C. O método de análise hierárquica AHP - como auxílio na determinação da vulnerabilidade ambiental da bacia hidrográfica do rio Piedade (MG). Revista do Departamento de Geografia, São Paulo, 23:4-26, 2012.

POMPERMAYER, R. de S. Análise multicriterial como instrumento de gestão de recursos hídricos: o caso das bacias dos rios piracicaba, capivari e jundiaí. Revista Brasileira de Recursos Hídricos, Porto Alegre, v. 2, n. 3, p.117-127, 2007. 
REMPEL, C.; ECKHARDT, R. R.; SCHULTZ, G.; PÉRICO, E.; CYRNE, C. C. S. Zoneamento ecológico-econômico - ZEE - para sistemas orgânicos de produção agropecuária. Tecno-lógica, Santa Cruz do Sul, v. 16, n. 2, p. 9097,2012 .

http://online.unisc.br/seer/index.php/tecnologica/article/view/3178/2392. Acesso em 23 de fevereiro de 2015.

ROSOT, M. A. D.; OLIVEIRA, Y. M. M.; MATTOS, P. P.; GARRASTAZU, M. C.; SHIMIZU, J. Y. Monitoramento na Reserva Florestal da Embrapa/Epagri (RFEE) em Caçador, SC. Paraná: Embrapa Florestas. 2007. 35p.

SARTORI, A. A. C.; ZIMBACK, C. R. L. Recomposição florestal visando à conservação de recursos hídricos na bacia do Rio Pardo, SP. Revista de Energia na Agricultura, Botucatu, v. 26, n. 4, p. 43-53, 2012. Disponível em: http://energia.fca.unesp.br/index.php/energia/article/view/300/190. Acesso em 25 de fevereiro de 2015.

SAATY, T. Scaling method for priorities in hierarchical structures. Journal Mathematical Psychology, Estados Unidos, v. 15, p. 234-281, 1977.

SILVA, C. L.; ANDERSEN, S.; KASSMAYER, K. Avaliação comparativa de três políticas ambientais no estado do Paraná: o ZEE, o GERCO e políticas de incentivo à agroecologia. Revista paranaense de desenvolvimento, Curitiba, v. 122, p. 95-122, 2012. Disponível em:

http://www.ipardes.pr.gov.br/ojs/index.php/revistaparanaense/article/view/474/7 03. Acesso em 22 de março de 2015.

TAVANTI, D. R.; MOURA, S.; AZEVEDO, F. Z.; MEDVEDCHIOFF, T. G.; DEUS, L. R.; MOREIRA, M. A. A.; LORAND, R.; CANCADO, C. J.; MARTINS, M. M. R. Estudo da Vulnerabilidade de Contaminação de Aquífero por Agrotóxicos, na Região de Descalvado e Analândia (SP). Revista Brasileira de Recursos Hídricos, Porto Alegre, v. 14, n. 1, p. 53-61, 2009.

THOMAS, B. L. Proposta de zoneamento ambiental para o município de Arroio do Meio - RS. RA'EGA,Curitiba, v. 24, p. 199-226, 2012. Disponível em: http://ojs.c3sl.ufpr.br/ojs- 2.2.4/index.php/raega/article/view/26215. Acesso em: 9 de janeiro de 2015.

VALENÇA. Decreto no 424, de 08 de maio de 2007. Dispõe sobre a reestruturação da Área de Proteção Ambiental de Guaibim, no Município de Valença e dá outras providências. Valença, 2007.

VALE, R. C. M.; LOBÃO, J. S. B.; ROCHA, W. J. S. F.; NOLASCO, M. C. Contribuições das geotecnologias ao zoneamento ambiental do setor sul do Parque Nacional Chapada Diamantina/BA. Revista RA'E GA, Curitiba, v. 16, p. 149-165, 2008. Disponível em: http://ojs.c3sl.ufpr.br/ojs/index.php/raega/article/viewFile/10887/9930. Acesso em 10 de fevereiro de 2015. 
VASCONCELOS, V. V.; HADAD, R. M. MARTINS JUNIOR, P. P. Methodologies for integratedstudies of natural resources: a discussiononecological-economiczoning. Pesquisas em Geociências, Porto Alegre, v. 40, n. 1, p. 21-30, 2013. Disponível em http://www.ufrgs.br/igeo/pesquisas/4001/2-4001.pdf. Acesso em 13 de fevereiro de 2015.

VEIGA, J. E. Desenvolvimento territorial: do Entulho varguista ao zoneamento ecológico-econômico.Salvador: Superintendência de Estudos Econômicos e Sociais da Bahia, 2001.

VILLA, F.; TUNESI, L.; AGARDI, T. Zoning Marine Protected Areas Through Spatial Multiple-Criteria Analysis: the Case of the Asinara Island National Marine Reserve of Italy. Conservation Biology, Cambridge, v. 16, n. 2, p. 515526, $2002 . \quad$ Disponível em http://www.uvm.edu/giee/pubpdfs/Villa 2002 Conservation Biology.pdf.

Acesso em 23 de março de 2015.

ZAHIRIAN, A.; PADASH, A.; SEYED, A. J.; ZAMANPOUR, M.; NABAVI, S. M. $B$. Wetland Zoning to Establish Land Conservation Using MCE Method (Case Study: Parishan Wetland, Iran). Advances in Environmental Biology Ammam, v. 6, n. 3, p. 931-939, 2012.Disponível em http://www.aensiweb.com/old/aeb/2012/931-939.pdf. Acesso em 16 de janeiro de 2015.

ZHANG, Z.; SHERMAN, R.; YANG, Z.; WU, R.; WANG, W.; YIN, M.; YANG, G. XIAOKUN, O. Integrating a participatory process with a GIS-based multicriteria decision analysis for protected area zoning in China. Journalfor NatureConservation,Estados Unidos, v. 21, p. 225 - 240, 2013.

ZUFFO, A. C.; REIS, L. F. R.; SANTOS, R. F.; CHAUDHRY, F. H. Aplicação de Métodos Multicriteriais ao Planejamento de Recursos Hídricos. Revista Brasileira de Recursos Hídricos, Porto Alegre, v. 7, n. 1, p. 81-102, 2002. 